\title{
10 Positive Change and Transgenerational Relationships in Family Business
}

\begin{abstract}
Italy is a country of small and medium sized enterprises, located contemporarily within local-regional culture and in the international commercial network. A great part of these enterprises are run by single families, involving all family members: this is at the same time both a strength and weakness, as family links can, by one side, improve the individual engagement in work, but may also, on the other side, affect the climate of the whole workspace with incorrect and stressing relational dynamics borrowed from the previously established family relationship. In this chapter the authors discuss the family system as a bio-cultural mechanism and present the role of good management based on Flow theory and its applications.
\end{abstract}

Keywords: Transgenerational relationships; Flow transmission, Family business.

\subsection{Introduction}

The family is an exceptional instrument for the transmission of information: within which both the genetic and cultural heritages are transmitted. This social structure has taken on varied myriad of forms over the centuries and between different countries, yet some universal traits recur: the tendency for procreation, the safeguard of the survival of the children, their education according to the main principles of a given culture. In general terms and from an evolutionary point of view, human beings and the groups they form and of which they are part (for example, the family) develop by means of a bio-cultural process that brings an increase in capacity and complexity (Massimini \& Inghilleri, 1993; Massimini, Delle Fave \& Csikszentmihalyi, 1988). The mechanism of natural selection (Darwin, 1859) has allowed the human species to adapt to various environmental conditions and has produced biological and genetic changes that have led individuals and social groups to build artifacts and cultural products that can be transmitted through time and are increasingly complex. Once the genetic fundamentals are set that guarantee the possibility of developing a cultural system as complex as the human one, this evolves with the times, manner and content that are only partially attributable to the genetic system (Shennan, 2008), which in turn is likely to be conditioned by the cultural instructions (Rogers \& Ehrlich, 2008 - see also chap.1).

Some of the issues highlighted by Darwin on the genetic evolution are of particular interest outside of the biological context. By means thereof, the populations 
and, more generally, the flow of information, have been studied by social sciences from an evolutionist point of view, yet not in a reductionist manner. In this sense, the thought of Dawkins (1976/2006, 1982) is particularly interesting. Dawkins' argument starts from the consideration that the human species, due to the biological and cognitive characteristics of its mind, the outcome of evolution, was able to form a hereditary system of transgenerational transmission of information different from the genetic one, but just as powerful and lasting: a cultural form. The human mind is biologically able to conceive and build efficient replicators of cultural information that are transmitted over time because they are deposited outside of the individuals, in extra-somatic locations. This leads to the development of tools, family systems, social norms, religions, hunting and harvest techniques, agriculture, art, ideologies, institutions, and so on. These cultural elements, which are veritable basic units of culture, are defined memes, from the greek mimeomai which means "to replicate by imitation" (Blackmore, 1999; Dawkins, 1976). Other authors, on the contrary, use the broader term artifacts, including in this category both the material (an object) and intangible (an idea) products of culture (Cole, 1995; Inghilleri, 1999, Vygotskij, 1934/1962).

Dawkins identifies the three characteristics that have allowed genes to become successful replicators of biological information, even for millions of years, as: copying-fidelity, that is, the ability to make identical copies of the original; fecundity, that is, the ability to make a certain number of copies; longevity, that is, the ability to exist long enough to express the previous two properties, namely to make a certain number of copies faithful to the original.

Dawkins also points out the distinction between vehicles and replicators. The first are the containers of the information transmitted over time, whereas the latter make up the information that is actually replicated from one generation to another. The first is represented, in biology, by the cells of the organism, the latter by the genetic information contained in the DNA. The first die (from one biological generation to another), the latter survive (from generation to generation). The author lays emphasis on the following key point, that copying-fidelity, fecundity and longevity are the three general properties that make successful replicators, regardless of the type of information involved. In other words, genes are good replicators of a specific type of information - biological information. But other kinds of replicators can be identified which pertain to other types of information. As stated previously, it is precisely this biological evolution that has led to a second type of replicator. The extraordinary features of the central nervous system of the human species, the associated symbolic capacity, language, the ability to build long-lasting artifacts, have, in fact, led to the creation of memes, a new kind of replicator or unit of information transmission, in this case, not of biological but of cultural information. Within the memes too, we can distinguish the vehicle (for example, returning to the topic of interest here, the organization of a family system) from the replicator (the specific values, ideologies, and family customs). 


\subsection{The Family Business as Bio-Cultural System: Competition Between Memes and Genes and the Function of Flow}

It is no coincidence that we have introduced the family as an example of a memetic/ cultural system. As a matter of fact, it represents a case of extreme complexity as it conveys, according to Dawkins' thought, both biological information (genes transmitted from parents to children), and cultural information (values and lifestyles of the family culture). This process becomes increasingly complex where the family organizes itself around a specific cultural unit such as a company or a production activity. Considering family-run businesses, which can range from small businesses to large multinational companies, the biological system is complemented by a specific and well-defined cultural system characterized not only by values but also by practical production strategies. These structures, which are very popular in Italy, are now present in all the industrialized countries where the recent economic crisis has accentuated the exodus from large companies, fostering the emergence of smaller businesses (Cesaro \& Cancelli, 2004). In structures such as these the generations work side by side, the adult children and grandchildren work with their fathers or grandfathers, males work with females. The family owned company is, in other words, a complex vehicle of cultural and biological replicators.

We will address this issue starting from the basic consideration that neither genes nor memes, in this case neither the biological family nor the family company, are transmitted by themselves. As suggested previously (Csikszentmihalyi \& Massimini, 1985; Inghilleri, 1999; Massimini, Delle Fave \& Csikszentmihalyi, 1988) the two hereditary systems are reproduced and transmitted over time only by means of human action and the investment of psychic energy upon them. It is through the mechanism of psychological selection, as defined in the first chapter of this volume, that the processes of biological evolution and cultural evolution are carried out. By focusing cognition, motivation and emotion on specific biological or cultural entities, specific entities are maintained over time and are transmitted to the following generations. This is true for genes that are transmitted through specific processes of psychological selection (the choice of partners, the decision to procreate and educate children, the care for health). Indeed, this is also true for memes: for example, the decision to follow a rule, to buy an object, to keep a tradition alive, to preserve a monument or, indeed, to set up and then develop a business. As pointed out in the first chapter, these selection processes are based on the psychological ability to have meaningful experiences, such as the Flow of consciousness, when interaction occurs with specific elements, be they biological (the genes represented by the children) or cultural (different memes). It is therefore clear that when our mind and our experience encounter biological and cultural entities simultaneously, or bio-cultural entities as we have defined the family and the family business, the situation becomes complex. The processes of psychological selection may in fact be directed towards 
different possibilities, following only the biological interest, or only the cultural one, or both (bio-cultural interest), or paradoxically by denying them both.

The specific relationship between Flow and the memes characteristic of a company or a business activity has been studied specifically (Csikszentmihalyi, 2004; Cesaro, 2012). Here however, the issue will be addressed from a different point of view. We will start by considering that the experience of Flow can occur in the everyday life of an entrepreneur whose family members work in the company, within the different situations of bio-cultural interest that have been outlined above. In general terms we can imagine four possible situations from an experiential viewpoint:

- entrepreneurs who experience Flow in the family and at work

- entrepreneurs who experience Flow in the family and an absence of Flow at work

- entrepreneurs who experience Flow at work and an absence of Flow in the family

- entrepreneurs who experience an absence of Flow in the family and at work

In the first case the entrepreneur loves their work, links it to purposes higher than mere earning and finds optimal experiences in the company. Work becomes an important moment in life, able to provide moments of Flow. This, however, also occurs in the family, while being with the spouse and children in the evening, on weekends, on holidays, but also at the company if they work there. The person is thus able to invest psychic energy in an integrated manner on different objects, those pertaining to family affections and those pertaining to work and productivity. In the second case the person finds satisfaction and experiential fulfillment in the domestic sphere, at home, with the children, whereas the work and the company are factors of anxiety, stress, or in some cases boredom. These states may also affect the relationship with the family members if they work in the company. The third case represents the opposite situation. The work provides rewarding moments, stimuli, a meaning. The homecoming, the time spent with the children and the spouse outside of work, does not represent a positive experience, but rather entails a contrary situation. In the fourth case, the daily life, both at home and at the company, is experientially negative and an optimal psychological state is never achieved.

It should be emphasized that these four prototypical situations, which will be discussed later with concrete examples, inevitably involve important psychological processes, of satisfaction and of conflict. The conflict, since the family and the family business are bio-cultural entities, can also be understood as the struggle between the biological interest (the future of the children) and the cultural interest (the future of the company). In the case of satisfaction, we can expect an increase in the complexity of both the individual's inner Self and of the bio-cultural element represented by the family and the company. The result will be the attainment, on the one hand, of psychological well-being and development of economic well-being and development on the other. In case of conflict there are several options: either the conflict is solved in a positive way, or it endures with destructive effects on a psychological level for the people involved, and from the position of the company. However, the four situations 
should not be considered static and unchanging, but rather moments of a process during which the possibility of a change that can enable the creation of moments of Flow and thus of development, is always accessible. This too will be discussed in the cases considered below.

The state of Flow of Consciousness, as seen in the first chapter, is composed of several factors, each of which is necessary, but not sufficient in itself, to bring out the optimal experience. Summarizing, the factors necessary to achieve a state of Flow are: clear goals, immediate feedback, balance between challenges and skills, concentration on the situation, absence of self-observation, presence of intrinsic motivation, merging between action and awareness, sense of automatic control, altered sense of time, positive affective state, absence of boredom, and lack of anxiety.

We wish, however, to bring forward other variables that must be considered in the cases of family businesses that will be described below: the presence of a defined symbolic system, the relationship with the territory, the culture and values shared in the company and in the family, the characteristics of the physical structures in which the work is performed (factories, offices, laboratories, warehouses, etc.), existing technologies, and the system of rules upon which the relations rest.

\subsection{Family, Company and Flow}

The family is inherently complex: the components are not chosen but one can freely choose to accept the family constraints, thus partaking in its symbolic system, culture and values. Following the discussion of Csikszentmihalyi (1990), it can be stated that some factors are particularly important in order to achieve an optimal experience within a family:

\section{- Presence of intrinsic motivation:}

To provide, flow, a family has to have a goal for its existence. [...] positive goals are necessary to focus the psychic energies of parents and children on common tasks.

[...] For such goals to result in interactions that will help increase the complexity of Its members, the family must be both differentiated and integrated. (Csikszentmihalyi, 1990, p.180).

- Differentiation:

Each member achieves their goals and is free to develop their own unique traits, maximizing personal skills, defining in a personal way their own goals.

\section{- Integration:}

The guarantee that what happens to one person will affect all the others.

- Clear objectives in daily life:

In addition to long-term goals, it is imperative to have a constant supply of shortterm objectives (Csikszentmihalyi, 1990, p.180). 


\section{- Feedback:}

Family activities should also provide clear feedback. [...] keeping open channels of communication (Csikszentmihalyi, 1990, p. 181), to communicate the problems as well as the achievement of the objectives.

- Full sense of ability:

The balancing of challenges and skills is another factor as necessary in enjoying social relationships in general, and family life in particular, as it is for any other flow activity (Csikszentmihalyi, 1990, p.181)

- Positive affective state:

Csikszentmihalyi states that There are great opportunities for joy and for growth that can only be experienced in family life (1990, p.184). Unconditional acceptance is especially important to children.

In a company, by contrast, it is more likely that other factors define Flow: the vision, the dream of an entrepreneur, the partners who are chosen to achieve a goal, the satisfaction for the achievements accomplished, the visibility and recognition of power in a given market. The very idea of setting up the company or the need to innovate are often sufficient to feel well-being (Cesaro, 2004) and the entrepreneur's push for change is often an intrinsic motivation (Deci \& Ryan, 1985) and part of the basis of optimal experience.

Among the variables that we have most frequently ascertained in the presence (or absence) of Flow in the family and in the company, the culture should be mentioned as shield/protection for both systems. As recalled by Csikszentmihalyi:

One of the major functions of every culture has been to shield its members from chaos, to reassure them of their importance and ultimate success (1990, p.11).

In fact, this principle will emerge several times in our discussion, where the hypothesis of the simultaneous presence of strong shared culture and the state of Flow will be reaffirmed, in confirmation of the statement that:

When a culture succeeds in evolving a set of goals and rules so compelling and so well matched to the skills of the population that its members are able to experience flow with unusual frequency and intensity, the analogy between games and cultures is even closer (Csikszentmihalyi, 1990, p.81). 


\title{
10.4 The Case Histories
}

The following are case studies that tell stories of families and businesses with whom we have worked, studied and researched over the past 20 years and in which we have observed the dynamics described above.

\subsubsection{Story 1: From the Absence to the Creation of Flow in the Company and in the Family}

\begin{abstract}
The generational transition within family entrepreneurship is very often complex. We remember a family with two children, a common situation: the first is the one who works, is committed, follows in the father's footsteps, gives continuity, in other words, is reassuring, and looks ahead. The second is the creative one, funny, playful, enjoys life, is always late when - and if - at work, full of ideas, friends, travels and a vision of life based on the "here and now". Conflicts arise constantly. The parents suffer, and hope that things will settle down sooner or later. Instead, the sons-in-law, daughters-in-law and grandchildren get involved: the first complicate things; the younger ones, on the other hand, give a renewed hope for a better future. The real help that can be offered to all of them is to try to protect the roots, defend the heritage and speak out. As in jealousy, resentment, fear, one forgets to tell the motivations for the achievements, mistakes, dreams and disappointments.
\end{abstract}

In this situation the optimal experience in the family was affected mainly by the lack of a positive affective state, not so much because of the parents, but because of the conflict between the children. At the same time, the differences in values and culture prevented them from having clear goals, especially at the family level. In addition to this, the balance between challenges and skills is not recognized by any of the family members involved. So, with these preconditions, it is very unlikely that an optimal experience can be fostered in the company, or at least, not until the conflict between the children is resolved, often with the removal of one of the two. Although the family of origin was lacking some of the elements to allow the emergence of the Flow, the latter can still be transferred to the new family, so that the heirs obtain optimal experience - that's what happens in the second part of the story.

"I never forget that I got as far as fourth grade and even if I wanted to study, my family needed my job.” The roots, the sense of belonging to an identity that was never repudiated, had always been that father's strong point. He always carried within himself the customs, traditions and values of a rural culture. Start early in the morning, work hard and intensely until five in the evening, but then always remember that "life is not just work, but also". These were the rules. After the hard work comes the family, friends, the Church, physical activity, the participation in rituals, a walk in the city center. These are simple and concrete activities that the generation of new managers and young entrepreneurs can hardly feel as being part of themselves, as true and basic elements of a life organized by the seasons and not by Google's agenda. The company was founded by 
the man who had used several occasions spending time on the market, in contact with people, seizing opportunities and alliances with other people with distinct backgrounds and skills. He had worked with his wife always beside him, with great tenacity and simple world views: perseverance, tenacity, reliability, a touch of cunning, a lot of luck after many a moment of economic difficulty; completely normal for someone who was born and has lived in the countryside. International success had never made that man forget the system of rules and the basic values for which he was recognized and appreciated: a rough person but sincere and reliable. The children, initially involved in equal manner within the company, in time took two different roads: the one imitating in his own way the rules and habits of the father, the other preferring a concept of delegation of the daily management to external managers, enjoying the fruits of the success achieved by the family. The "cultural" conflicts soon led to a climate of tension and unease in all three families, the original one and the two families which the two youngsters had in the meantime created. The final break came when the youngest decided to create a new, creative company like his father's, but with modern styles and views. Work rules were clear and communicated to all employees and customers who shared these goals and values. The well-being flowed year after year together with the positive results. Within the family that state was enjoyed to the full. Leaving had been the only way to regain a positive state.

In this case, we can see that the creation of a new company and thus of a new challenge, laid the groundwork for an optimal experience in the company. The feedback is immediate, the goals are well defined and the relational climate is decidedly positive. All this entails a positive impact on the family as well. In fact, the Flow of the company in time pours into the new family created by one of the children. In the families of origin, on the contrary, too many aspects were missing for an optimal experience to arise, starting from a negative emotional basis, the lack of an adequate feedback and the inconsistency of common and clearly shared objectives. It is interesting to note that the charge of psychic energy that the Flow involves and the feeling of well-being connected to it can have consequences on the family too (Cesaro, 2011), emphasizing yet again the strong bond that exists between family and business.

\subsubsection{Story 2: Initial Presence of Flow in the Family, Lack of Flow in the Company and Consequent Discomfort in the Family as Well}

If the core values in the company are declared but it is not possible to put them into practice and the original values of the parents are adhered to by the family due to the daily strain experienced at work, the persons, both the old and young, feel bad in both contexts. Often psychosomatic illnesses emerge; Flow does not occur neither in the family nor in the company and this creates problems that do not allow the realization of any experience of well-being.

We could not understand why everyone in that family felt so bad: the discomfort could be perceived right in their physique. Body and mind were entwined in a discomfort which was expressed every time they had the opportunity to talk about it in private with their closest friends and a 
few trusted consultants. Theirs was a financially healthy company with a solid position in the international market, despite having started from nothing, simply as a response to the parents' desire to succeed. They were both eager to redeem themselves from various difficulties suffered during youth, in their families of origin, due to the uncertain economic conditions as well as to premature bereavements. Year after year, however, the organizational climate was becoming increasingly tense and the evident and hidden conflicts wore the relationships out, day after day, at all levels. The communication between people was mainly handled by the father, who had always practiced the principle of trust and generosity toward employees and customers. His style was that of the "domineering father" apparently able to control and decide everything in the company and in the family. The mother was a "volcano of creativity", dynamic and involved in every possible initiative, curious and eager to enjoy every opportunity that life had to offer. The children had a strong bond with the territory, great respect and gratitude for the parents but, other than executing orders, had never experienced the feeling of autonomy and responsibility. They eventually developed a lack of confidence in themselves and, gradually, in others. All their decisions were contradicted every day and the feeling of insecurity and organizational confusion was in contrast with the image of positivity and confidence that the brand communicated on the market. Parents and children could not explain their inability to communicate: "Sorry if I'm not the son you wanted" was the unspoken sentence that echoed every day from the now young adults who were trying to find compensation for their discomfort outside the company and the family, moreover without great results. "What did we do wrong?" was, instead, the recurring thought in the conversations between the parents, shifting responsibilities and disappointments to one another for a situation too overwhelming for their capacities and energies, now waning as time went by. Sell the company? Entrust it to a manager? Run the risk of demolishing it under the weight of the tensions, sufferings and difficult relationships that had already defiled employees and customers? The feeling was that only a precipitating event, a shock, a bereavement, could make them stop and bring order and a little peace, perhaps after a period of further suffering. The hope was that a consultant or a - very - positive event from the outside such as a birth could light up the gray and painful climate that accompanied their solitudes, furthermore, lived in gilded cathedrals.

In this case, it is clear that the lack of a positive affective state is a hindrance to laying the groundwork for Flow to occur in the family. At the same time, the absence of feedback in the family blocks the occurrence of Flow within the company, spreading a sense of inadequacy and low self esteem among the family members. Consequently, the balance between challenges and skills does not occur, triggering a high state of chronic anxiety that often involves psychosomatic illnesses too. All of this has repercussions for the collapse of the intrinsic motivation, as well as the lack of clear goals in the company as in the family. Finally, the parents' lack of unconditional acceptance of the children was a serious detriment to the development of an optimal experience.

The second part of this case, however, gives new hope: some of the founding values of the family found acknowledgement in the behavior of the children and endured the difficulties at least until a partial solution of the problems. This came about when the social engagement and corporate social responsibility were put into play. The father's habit of "doing charity" in silence, following old-time Christian ethics, was combined with the desire of one of the children to be engaged as leader of an international solidarity project. In those years there were several proposals for financings to benefit from tax breaks or promotion. That is how, at a meeting of entrepreneurs, a project for 
social assistance was presented, based on the family values and not as a mere business project. "Donating a share of our profits is giving meaning to what we do every day: I have learned this as well from my parents". No advertising would be done. In different ways, the family styles and values were perpetuated, thus creating psychological and economic well-being.

\subsubsection{Story 3: Flow in the Family, Flow in the Company. The Case of Acquisitions and the Value of Corporate Culture}

In the companies, the continued demand for psychic energy necessary to face the adjustments of conduct and organization urged by the state of evolution or crisis within the market, brings the individual to play an active role by committing their own personal resources and skills, pleased with their operations, focusing their attention and increasing their state of well-being and their professional background. Or, conversely, the individual may suffer from the situation, passively performing the duties assigned (in a sort of perpetual state of routine). In the latter case it will not be possible to reach a state of balance, since the person, in the long run, will perceive their ability to face and solve problems as being higher than required (Cesaro, 2011) and are therefore unable to reach the Flow state if not stimulated with new goals to reach. So as to understand the first hypothesis (that of participating actively in the change) we present a letter written by an employee of a company which, after a difficult acquisition, was able to transfer the family values within the organization.

I gladly remember the first day of work as if it were yesterday. After all, a year goes by quickly but, little as it is, we have seen things change a lot. The key words today are "innovation - novelty - change - evolution - keep up with the times" or rather these represent our owner. Visible changes, starting from the smaller things, up to the real innovations: modern machinery, capable of giving quality and volume in an increasingly competitive market, and improvements on an individual and collective level in a group driven to a greater open-mindedness. The ensemble of all these innovations, represents for us newcomers a strong stimulus for radical change. Not only did the "friend money" contribute to give importance to our daily lives, but it was also important to see growth in a company with the desire to grow. Another key factor in the development of a company is the family, very much felt in this company, but also from mine and I think from all of ours. The family means help, understanding, support, security, future, and so much more that fills the life of each of us. There is one thing I am certain of now: my job which, despite the crisis and the negative aspects of the reality that surrounds us, is what allows us to live, think and act more serenely with an eye on a future with better prospects.

It may also happen that the family has all the features that allow the presence of Flow, thanks to a strong culture of shared values, and is not able to transfer this symbolic system into the company, often due to real contrasts between different cultures as in the case of acquisitions or mergers with other companies, or when economic market 
crisis bring the small family businesses face to face with financial problems. The creation of alliances and business networks can help overcome the economic problems but this often drives persons to identity crises that threaten their sense of belonging and, in the long run, the intrinsic motivation for working well. The case comes to mind of a company that had absorbed a competitor, whose owners were members of a family with an equally important history and experience, but with totally different values, style, and languages. This second company was in serious difficulty due to the economic crisis, the internal climate was very tense and communication was limited to operational needs. The relationships between the employees were saddened by personal events, by bereavements and a "lapse" into mere production activities. Relations with the outside world were limited to mutual convenience, to the quality of the product and to times of hard work. Year after year, everything had clouded: the faces of the persons, the walls of the company, and the results of the financial statements. Yet all the family members involved in the organization appreciated and supported each other, though, outside of work, they had made different life choices and chosen different values. They met at the factory, but lost sight each other in everyday life. Perhaps they were incapable of processing their common grief and their difficulties in the market, but most of all they had forgotten how to smile and their juvenile buoyancy. There was simply no communication, and the collaborators had followed them down this road. Selling the company not only had the meaning of saving what could be saved from the point of view of the assets, but it had been an opportunity to be invigorated with a new energy. But initially it was not so: the two different family cultures collided and for a couple of years the relations were agonizing and frustrating. Conflicts and organizational confusion would have worn down the entire system, but for the commitment of the new family in wanting to reaffirm the consistency of the principles and values that characterized it. In this case we have a family with a strong positive affective state. The culture (corporate in this case) can effectively be the shield and the vehicle through which it is possible to protect the members from chaos, reassuring them of their importance and finalizing the success of their actions (Csikszentmihalyi, 1990).

\subsubsection{Story 4: Flow in the Family, Flow in the Company. Well-Being Created Also by the Ability to Face and Overcome Grief and Shock.}

In the following case we find optimal experience that concerns both the family and the company mainly through the rituals, traditions, and the symbolic system of the family.

We were all sitting around the kitchen table with the father. In his bathrobe and with the spontaneous smile on his face, hollowed by suffering, his eyes shined as always. The disease had 
worn him out only in the body but the spirit was very strong. We were about to start our meeting to decide the future of that family. The documents and the notary were ready, to ensure the correctness of the decisions made for the future of children and grandchildren. The mother stopped us and asked for a silent prayer: the only embarrassed person was the notary. He wondered about the meaning of such a private and intimate rite in a business meeting. But we knew the importance of rites, those which sanction commitment to the values of that family. The economic wealth of the family was mostly invested in a group of companies where the daily activity involved persons who could feel they were part of a project, a path to which they clung because they shared primarily the values that the family represented. Most of the customers and suppliers had a clear image of the principles, ethics, and the example of that father to whom the children referred, especially in times of difficulty. The climate entailed was predominantly positive.

We recall another case:

Sadness filled the room. He had died a few weeks before: she had followed him into an entrepreneurial venture made of commitment, sacrifice, and eventually rewards. The young children had completed their studies, and two of them were on the gateway to work, ready to commit themselves and understand if that was to be their path, their enterprise. Then suddenly tragedy struck. We needed the courage to go on: that was what employees, consultants and shareholders hoped for, in profound hard-working silence. There was the history, the culture, the bond with a territory that was small but still original, authentic, that clutched tightly around that family. And that was their starting point. They all worked hard and within a few years they developed a successful activity, starting from the experiences and values of the family and giving expression, within that company, to the heritage of their popular culture. After several years of collaboration we met in those modern, bright, smiling offices: on the wall hung the photograph of that smiling man, a positive example for those children, now "captains" of a vital and generous organization. The deep-rooted origins had drawn their strength from a family renewed by a number of true passions around which everyone recognized themselves.

In this "optimal" case all the elements of Flow were present in the family and by means of clear goals, immediate feedback, a positive affective state and a strong intrinsic motivation it was possible to transfer the optimal experience to the organization as well. The vehicle for this transfer is contained explicitly in the culture, in a strong system of symbols and in the values shared in the family and company, but also in the possibility to feel capable and motivated within the roles and moments of the family, as fathers, mothers and children.

\subsection{Conclusions}

The case studies reported above suggest that the presence of Flow in one of the two systems, family and company, may affect the other. It is possible that an optimal experience in the family influences the company and vice versa; at the same time the opposite is also possible, that is the lack of Flow can have a negative impact where Flow has never occurred or has occurred in the past and is failing. Another aspect, 
implicit in the stories reported, is pointed out: when Flow is present, there is not only a positive correlation with the well-being perceived but also a better economic return and a more relaxed business climate, which helps productivity. The optimal experience, endowed with meaning and source of well-being, brings with it a eudaimonic idea: personal happiness and development of the organization and of the community combine in the direction of good work (Gardner, Csikszentmihalyi \& Damon, 2002) and good business (Csikszentmihalyi, 2004).

\section{References}

Blackmore S. (1999). The Meme Machine, Oxford: Oxford University Press

Cesaro F. (2004) Piccoli e scatenati. Formazione, ricerca e consulenza per le piccole organizzazioni. Milano: Guerini \& Associati

Cesaro F. (2012) L'ho fatto per voi. Storie di aziende famigliari che nascono, crescono e muoiono. Milano: Guerini \& Associati

Cesaro F. \& Cancelli, S., (2004), Gruppi in azione: le piccole aziende famiglia del nord e lo sviluppo della società, in DIPAV, Quaderni, Quadrimestrale di Psicologia e Antropologia Culturale, 11, 71-92

Cesaro F., Bini M. (2011) Racconti di fabbrica. Narrazioni attorno al lavoro quotidiano. Milano: Guerini \& Associati,

Cole, M. (1996), Cultural psychology: a once and future discipline, Cambridge: Belknap Press

Csikszentmihalyi, M. (1990) Flow. The psychology of optimal experience. New York: HarperPerennial

Csikszentmihalyi M. (2004). Good Business: Leadership, flow, and the making of meaning. New York, NY: Penguin Books

Csikszentmihalyi M. \& Massimini F. (1985). On the Psychological Selection of Bio-Cultural Information, New Ideas in Psychology, 3, 115-138

Darwin, C. (1859). On the origin of species by means of natural selection. London: John Murray Dawkins, R. (1982). The extended phenotype. Oxford: W.H. Freeman \& Co.

Dawkins, R. (1976/2006). The selfish gene. New York: Oxford University Press

Deci E. L., Ryan R. M. (1985) Intrinsic motivation and self-determination in human behavior, New York: Plenum.

Gardner, H., Csikszentmihalyi, M., \& Damon, W. (2002). Good business: leadership, flow, and the making of meaning. New York: Basic Books.

Inghilleri P. (1995) Esperienza soggettiva, personalità, evoluzione culturale. Torino: UTET

Inghilleri, P. (1999). From subjective experience to cultural change. New York: Cambridge University Press.

Massimini F. \& Inghilleri P. (Eds.). (1993). La selezione psicologica umana. (Human Psychological Selection), Milano: Cooperativa Libraria IULM

Massimini F., Csikszentmihalyi M. \& Delle Fave A. (1988). Flow and biocultural evolution, in: Csikszentmihalyi M. \& Selega Csikszentmihalyi I. (Eds.) Optimal experience. Psychological studies of flow in consciousness, New York: Cambridge University Press.

Rogers, D. S., \& Ehrlich, P. R. (2008). Natural selection and cultural rates of change. Proceedings of the National Academy of Sciences of the United States of America , 105 (9), 3416-3420. 
Shennan, S. (2008). Canoes and cultural evolution. Proceedings of the National Academy of Sciences of the United States of America , 105 (9), 3175-3176.

Vygotskij L. (1934/1962). Thought and language. Cambridge: MIT Press. 